\title{
Ahorro en los hogares de México: ¿importa el lugar de residencia?*
}

\author{
Isalia Nava Bolaños ${ }^{\star \star}$ \\ Gonzalo Esteban Negreros Amaya ${ }^{\star \star \star}$ \\ Abraham Granados Martínez ${ }^{\star \star \star \star}$
}

En este artículo se analiza el perfil de ahorro de los hogares rurales y urbanos en México. A partir de la Encuesta Nacional de Ingresos y Gastos de los Hogares de 1994 a 2014 se construye un panel sintético y se estima un modelo semiparamétrico que permite identificar los perfiles por edades. Los resultados contrastan con la hipótesis del ciclo de vida, el perfil por edades no muestra una forma de $U$ invertida, hay evidencia de mayor ahorro en las edades avanzadas. Los perfiles de ahorro son mayores en los hogares urbanos, en particular en aquellos con personas mayores y acceso a la salud.

Palabras clave: Hipótesis del ciclo de vida. Modelo semiparamétrico. Pseudopanel.

\footnotetext{
* Esta investigación se realizó en el marco del Proyecto del Consejo Nacional de Ciencia y Tecnología (CONACYT) 255008 "Cambio en la estructura por edades, ahorro y seguridad social en México".

Los autores agradecen el apoyo del maestro Sebastián Antonio Jiménez Solís, por su colaboración en la búsqueda y revisión de estadísticas.

** Instituto de Investigaciones Económicas, Universidad Nacional Autónoma de México (IIEc-UNAM), Ciudad de México, México (isalia@unam.mx; https://orcid.org/0000-0001-8317-4601).

*** Facultad de Economía, Universidad Nacional Autónoma de México (FE-UNAM), Ciudad de México, México (estebanegreros@ outlook.com; https://orcid.org/0000-0002-0386-0968).

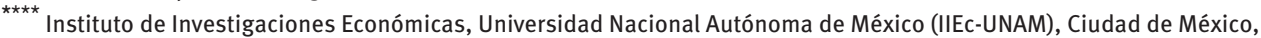
México (abraham.granados@iiec.unam.mx; https://orcid.org/0000-0001-7842-9091).
} 


\section{Introducción}

Las localidades rurales en México presentan condiciones adversas en términos económicos y sociales. Además de que las crisis suelen impactar y ahondar la desigualdad en los lugares que presentan las condiciones menos ideales. Gustavo Gordillo y Thibaut Plassot (2019) confirman que las desigualdades territoriales han creado trampas de pobreza, generando una alta heterogeneidad de los ingresos. Es así que desagregar por localidad de residencia rural/urbana resulta relevante porque los hogares rurales presentan menores niveles de ingreso en comparación con los urbanos (SZÉKELY; MÉNDOZA, 2016). La variabilidad que presenta el ingreso no permite que los hogares rurales consoliden un ahorro consistente a lo largo de su vida, factor que sí puede encontrarse en los hogares urbanos, aunque con matices. Aunadas al proceso de envejecimiento que presenta la población, con la transición demográfica, las brechas de desigualdad tienden a ampliarse.

Este panorama de envejecimiento de la población supone desafíos como que las personas en edades avanzadas deban mantenerse económicamente activas y que en las localidades rurales la incertidumbre económica se profundice (SANCHEZY; PACHECO, 2012).

El objetivo de este trabajo es estimar y analizar los perfiles de ingreso, gasto y ahorro de los hogares mexicanos y las diferencias entre los hogares urbanos y rurales, adicionando dos características más: la primera, la presencia de personas en edades de sesenta años y más (p60+) en el hogar; la segunda, el acceso a la salud como una variable determinante del ahorro.

Con la información de la Encuesta Nacional de Ingresos y Gastos de los Hogares (ENIGH) 1994-2014 se construyó un panel sintético o pseudopanel utilizando el año de nacimiento del jefe del hogar para generar los perfiles de ingreso, consumo y ahorro tanto para hogares urbanos como rurales. Las motivaciones para realizar esta investigación fueron que durante este período de estudio, en materia de lucha contra la pobreza los resultados han sido mínimos (SZÉKELY; MÉNDOZA, 2016), por lo que suponemos que si las brechas de desigualdad se intensificaron fue por carecer de mecanismos redistributivos que pudieran auxiliar a los hogares, como el acceso a la salud, lo que generó un desahorro en los hogares rurales con población envejecida.

Este documento se divide en cinco secciones. En la sección I se presenta una breve revisión de la bibliografía. En la sección II se explica la relevancia del ahorro a lo largo de la vida, donde se integran los factores sociodemográficos de los hogares. En la sección III se describen la fuente de información y el modelo semiparamétrico empleados. En la sección IV se analizan los resultados obtenidos, y, finalmente, en la sección V se presentan las conclusiones.

\section{Breve revisión de la bibliografía sobre ahorro en México}

Una de las teorías más utilizadas en el análisis del ahorro es la hipótesis del ciclo vida (HCV) planteada por Franco Modigliani y Richard Brumberg (1954). De acuerdo con esta 
hipótesis, los individuos obtienen un ingreso por trabajo que se vuelve ascendente conforme van mejorando sus oportunidades laborales, hasta llegar a un punto máximo a partir del cual se reduce hasta que desaparece al momento del retiro de la actividad económica, mientras que el consumo tiene una tendencia constante a lo largo de la vida. Por lo tanto, el ahorro tendrá un comportamiento en forma de U invertida: en el período laborable los individuos ahorran y durante el retiro desahorran.

Entre las investigaciones que analizan el ahorro para el caso de México y que retoman el concepto de ciclo de vida se identifican dos grandes aproximaciones: desde una perspectiva transversal basada en el enfoque de transferencias intergeneracionales y a partir de un análisis dinámico basado en cohortes sintéticas.

Entre los estudios que retoman las transferencias como marco teórico conceptual, estas parten de considerar el intercambio de recursos económicos entre diferentes generaciones. En especial, las cuentas nacionales de transferencias (NTA, por sus siglas en inglés) permiten estimar y analizar los flujos de recursos entre distintas edades, garantizando que los conceptos sean compatibles a nivel agregado (LEE; MASON, 2011). Iván MejíaGuevara $(2008,2011,2014)$ estudia el ciclo de vida económico a partir de la construcción de los patrones por edad del consumo y los ingresos laborales, para lo cual conceptualiza como el déficit del ciclo de vida (DCV) a la diferencia entre ambas variables. Como parte de sus hallazgos para el período 1992-2010 destaca la presencia de un patrón en forma de $U$ invertida del ingreso, pero con valores significativos en las edades avanzadas y una distribución plana del consumo. Además, un rango muy corto de superávit entre los 16 y los 29 años, es decir, a las edades en las que el ingreso laboral medio es mayor al consumo (MEJÍA-GUEVARA, 2014).

En el marco de la economía generacional, Iván Mejía-Guevara y Verónica Murguía (2012) revisan también como se modifican los perfiles de ingreso, consumo y DCV a lo largo del horizonte de vida, tomando en cuenta las tasas de participación laboral, la educación (RENTERÍA et al., 2016) y las diferencias en el estatus socioeconómico (MEJÍA-GUEVARA, 2015), así como el papel de las políticas de protección y de seguridad social (MEJíAGUEVARA; FERNÁNDEZ VARELA; GARCÍA LÓPEZ, 2010). En una investigación más reciente Iván Mejía-Guevara, Estela Rivero e Isalia Nava (2019) agregan a los perfiles de ingreso laboral, consumo y DCV, la producción y el consumo domésticos.

Mientras tanto, las investigaciones que analizan el ahorro a partir de la construcción de cohortes sintéticas consideran el componente intrínsecamente dinámico que caracteriza a la variable. Orazio Attanasio y Miguel Székely (1999) examinan el comportamiento del ahorro de los hogares y la distribución del ingreso con base en las ENIGH 1984-1996. Los autores encuentran que el ahorro privado aumentó durante la crisis inflacionaria (19841994) y disminuyó en el período de apertura comercial (1994-1996). Además, el ahorro se concentra entre quienes presentan mayores niveles de escolaridad y son estos hogares los que muestran perfiles de ahorro más cercanos al planteamiento de la HCV. Fernando Solís y Alejandro Villagómez (1999) revisan el comportamiento del ahorro en un esquema 
de pensiones de reparto, a partir de las ENIGH desde 1984 hasta 1996, y encuentran un efecto negativo que se refleja en una caída del ahorro, que no describe un perfil de $U$ invertida. Isalia Nava (2015) también analiza las diferencias en los perfiles de ahorro de la población ocupada según condición de acceso a la seguridad social. La autora tampoco halla que el ahorro describa un perfil como el que plantea la HCV. Además, quienes carecen de seguridad social presentan tasas de ahorro menores.

A diferencia de las investigaciones anteriores, Ricardo Fuentes y Alejandro Villagómez (2001) consideran la localidad de residencia como variable control. Los autores estudian el comportamiento del ahorro de los hogares de bajos ingresos a través de las ENIGH entre 1984 y 1996 . Al dividir a la población según localidad de residencia, como variable proxy del ingreso, encuentran que en las zonas rurales las tasas de ahorro resultan mayores durante todo el ciclo de vida y, además, el ahorro se mantiene en el último tramo de la vida productiva, aspecto que los autores entienden que está motivado por la precaución. Alejandro Villagómez y Andrés Zamudio (1997) analizan el comportamiento del ahorro en los hogares rurales, a través de las ENIGH de 1984 a 1996, y observan que los perfiles no ilustran una forma de $\mathrm{U}$ invertida, sino que más bien describen una tendencia decreciente.

Estas investigaciones coinciden en construir cohortes sintéticas para analizar el perfil de las personas a lo largo del tiempo y en hacer una descomposición estadística de los efectos cohorte, período y edad retomando el modelo propuesto por Angus Deaton (1997). En un trabajo más reciente, Owen Ceballos (2018) caracteriza el comportamiento del ahorro y de pago de deuda de los hogares a partir de las ENIGH entre 2000 y 2014. Si bien también utiliza cohortes sintéticas, a diferencia de las investigaciones previas estima un modelo semiparamétrico lineal-parcial, para concluir que hacia el final del ciclo de vida el ahorro es elevado y sostenido.

Finalizada esta revisión, el artículo analiza los perfiles de ahorro de los hogares a lo largo del ciclo de vida, es decir, en un contexto dinámico que permita seguir el comportamiento de la variable a lo largo del tiempo.

\section{Consideraciones sobre el ahorro, las personas mayores y su localidad de residencia}

En la bibliografía sobre ahorro no hay consenso sobre el comportamiento de la variable a lo largo del ciclo de vida ni específicamente sobre el hecho de que las personas ahorran en las edades activas y laborales y agotan sus activos cuando son mayores. Como plantea Deaton (2005), las personas mayores no disponen de sus activos de la forma que plantea la teoría, sino que es común el ahorro en las edades avanzadas o el inicio del ahorro previo a las edades de retiro de la actividad laboral. Axel Börsch-Supan y Konrad Stahl (1991) hacen referencia a la noción de restricciones de consumo, caracterizadas por la presencia de una utilidad marginal decreciente del consumo conforme los hogares envejecen, que los autores atribuyen al deterioro de la salud. Se trata de un tema que adquiere relevancia dado el acelerado proceso de envejecimiento demográfico. 
A nivel macroeconómico, si los hogares con personas mayores no ahorran, el cambio en la estructura poblacional tendrá efectos negativos, ya que implicará una disminución en la tasa de ahorro privado. Por el contrario, si acumulan riqueza es probable que la tasa de ahorro aumente, generando efectos positivos sobre la acumulación de capital (BÖRSCHSUPAN, 1992) y, en consecuencia, sobre el crecimiento económico y el desarrollo de los países (DEATON, 1997). Por otro lado, en lo microeconómico el ahorro se convierte en consumo futuro y va encaminado a enfrentar la incertidumbre a medida que se presentan pérdidas en las capacidades y quebrantos en la salud propios del proceso de envejecimiento (HAM, 2003). Por lo tanto, en esta investigación se reconoce la relevancia de considerar los perfiles de ahorro de los hogares con personas mayores.

En la revisión del ahorro a nivel individual y de los hogares, como se presentó en la sección anterior, se reconocen las marcadas diferencias según estrato socioeconómico. Una de las variables menos analizadas es la localidad de residencia, pese a que el nivel de ingreso y patrimonio neto acumulado a lo largo de la vida es marcadamente menor en las localidades rurales, al tiempo que la cultura del ahorro no es necesariamente monetaria (VÁZQUEZ; BARBOSA, 2013). Por lo tanto, es preciso preguntarse si existen diferencias en los perfiles de ahorro según la localidad de residencia.

Para el caso de México se estima que la población de sesenta y más años de edad representó $12 \%$ en 2020 y aumentará a 18,7\% en 2040. Los datos de la Tabla 1 también dan cuenta del proceso de envejecimiento de los hogares: mientras que en 1994 los hogares con al menos una persona de sesenta años y más representaron 19,7\%, en 2014 esta proporción aumentó a 25,2\%. Además, las cifras muestran las marcadas diferencias en la configuración de los hogares con personas mayores: se aprecia un incremento en la edad media del jefe(a) del hogar, un aumento en la participación de los hogares de jefatura femenina y una mejora en los niveles de escolaridad de los jefes(as) de hogar. Asimismo, la participación de los hogares nucleares disminuye, al tiempo que la de los unipersonales aumenta y se reduce el número promedio de sus integrantes menores (de cero a seis años) en el hogar. La localidad de residencia se mantiene constante: aproximadamente dos de cada diez hogares con personas mayores se encuentran en una localidad rural.

En relación con los hogares con personas mayores según condición de residencia, las cifras de la Tabla 2 muestran que la edad media de los jefes(as) se ha mantenido constante en las localidades rurales, entre 47 y 49 años, mientras que en las zonas urbanas se aprecian incrementos: en 1994 la media era de 44,1 años, pero para 2014 aumentó a 48,8 años, lo que da cuenta del proceso de envejecimiento demográfico. Además, si bien es cierto que predominan los hogares dirigidos por hombres, los porcentajes de hogares de jefatura masculina son más altos en las localidades rurales. Por otro lado, las localidades urbanas denotan marcadas mejoras en relación con la escolaridad: conforme avanzan los años los porcentajes de jefes(as) sin escolaridad o con primaria disminuyen significativamente. Mientras que en las localidades rurales las mejoras son menos notorias, en 2014 más de la mitad de los jefes(as) alcanzaban nivel primaria. Respecto al tipo de hogar, en 
las localidades urbanas se aprecia una marcada disminución de los hogares nucleares, al tiempo que aumentan los ampliados o compuestos, y sobre todo los unipersonales. Por el contrario, en las localidades rurales los hogares nucleares muestran incrementos en algunos años y los unipersonales registran ligeros aumentos.

TABLA 1

Características sociodemográficas de los hogares

México - 1994-2014

\begin{tabular}{|c|c|c|c|c|c|c|}
\hline Características & 1994 & 1996 & 1998 & 2000 & 2002 & 2004 \\
\hline Total de hogares & 19.212 .468 & 19.962 .929 & 21.626 .736 & 23.151 .556 & 24.531 .631 & 25.561 .447 \\
\hline Hogares sin personas de 60 años y más & 15.426 .154 & 16.166.974 & 17.254.961 & 18.133 .800 & 19.151 .097 & 19.836 .682 \\
\hline$\%$ & 80,3 & 81,0 & 79,8 & 78,3 & 78,1 & 77,6 \\
\hline $\begin{array}{l}\text { Hogares con al menos una persona } \\
\text { de } 60 \text { años y más }\end{array}$ & 3.786 .314 & 3.795 .955 & 4.371 .775 & 5.017 .756 & 5.380 .534 & 5.724 .765 \\
\hline$\%$ & 19,7 & 19,0 & 20,2 & 21,7 & 21,9 & 22,4 \\
\hline \multicolumn{6}{|l|}{ Sexo de la jefatura (\%) } & 46,9 \\
\hline Jefatura masculina & 85,0 & 83,0 & 82,0 & 81,0 & 80,0 & 77,0 \\
\hline Jefatura femenina & 15,0 & 17,0 & 18,0 & 19,0 & 20,0 & 23,0 \\
\hline \multicolumn{7}{|l|}{ Escolaridad del jefe del hogar (\%) } \\
\hline Ninguna & 17,0 & 14,0 & 13,0 & 13,0 & 15,0 & 12,0 \\
\hline Primaria & 46,0 & 47,0 & 46,0 & 44,0 & 41,0 & 42,0 \\
\hline Secundaria & 17,0 & 18,0 & 19,0 & 21,0 & 21,0 & 24,0 \\
\hline Preparatoria & 8,0 & 10,0 & 9,0 & 9,0 & 10,0 & 10,0 \\
\hline Universidad y más & 11,0 & 12,0 & 12,0 & 14,0 & 13,0 & 13,0 \\
\hline \multicolumn{7}{|l|}{ Tipo de hogar (\%) } \\
\hline Nuclear & 69,0 & 70,0 & 71,0 & 70,0 & 70,0 & 67,0 \\
\hline Ampliado o compuesto & 24,0 & 24,0 & 21,0 & 22,0 & 22,0 & 24,0 \\
\hline Unipersonal & 7,0 & 6,0 & 8,0 & 8,0 & 7,0 & 9,0 \\
\hline \multicolumn{7}{|l|}{ Promedios de integrantes } \\
\hline Menores & 1,3 & 1,2 & 1,1 & 1,0 & 1,0 & 1,0 \\
\hline Mayores & 3,2 & 3,2 & 3,1 & 3,0 & 3,0 & 3,0 \\
\hline Mujeres & 2,3 & 2,3 & 2,2 & 2,1 & 2,1 & 2,0 \\
\hline Hombres & 2,2 & 2,2 & 2,1 & 2,0 & 2,0 & 1,9 \\
\hline \multicolumn{7}{|l|}{ Localidad (\%) } \\
\hline Urbana & 77,0 & 78,0 & 78,0 & 78,0 & 76,0 & 77,0 \\
\hline Rural & 23,0 & 22,0 & 22,0 & 22,0 & 24,0 & 23,0 \\
\hline
\end{tabular}


(continuación)

\begin{tabular}{|c|c|c|c|c|c|}
\hline Características & 2006 & 2008 & 2010 & 2012 & 2014 \\
\hline Total de hogares & 27.445 .356 & 27.874 .625 & 29.556 .772 & 31.559 .379 & 31.671 .002 \\
\hline Hogares sin personas de 60 años y más & 21.307.984 & 21.100 .795 & 22.392 .359 & 23.370 .530 & 23.691 .455 \\
\hline$\%$ & 77,6 & 75,7 & 75,8 & 74,1 & 74,8 \\
\hline $\begin{array}{l}\text { Hogares con al menos una persona } \\
\text { de } 60 \text { años y más }\end{array}$ & 6.137 .372 & 6.773 .830 & 7.164 .413 & 8.188 .849 & 7.979 .547 \\
\hline$\%$ & 22,4 & 24,3 & 24,2 & 25,9 & 25,2 \\
\hline $\begin{array}{l}\text { Edad promedio del jefe(a) del hogar } \\
\text { Sexo de la jefatura (\%) }\end{array}$ & \multicolumn{4}{|c|}{ Sexo de la jefatura (\%) } & 48,8 \\
\hline Jefatura masculina & 75,0 & 75,0 & 75,0 & 75,0 & 74,0 \\
\hline Jefatura femenina & 25,0 & 25,0 & 25,0 & 25,0 & 26,0 \\
\hline \multicolumn{6}{|l|}{ Escolaridad del jefe del hogar (\%) } \\
\hline Ninguna & 10,0 & 10,0 & 9,0 & 9,0 & 8,0 \\
\hline Primaria & 40,0 & 40,0 & 38,0 & 36,0 & 34,0 \\
\hline Secundaria & 24,0 & 25,0 & 26,0 & 27,0 & 27,0 \\
\hline Preparatoria & 12,0 & 11,0 & 12,0 & 13,0 & 15,0 \\
\hline Universidad y más & 14,0 & 13,0 & 14,0 & 15,0 & 16,0 \\
\hline \multicolumn{6}{|l|}{ Tipo de hogar (\%) } \\
\hline Nuclear & 66,0 & 66,0 & 65,0 & 63,0 & 65,0 \\
\hline Ampliado o compuesto & 25,0 & 25,0 & 25,0 & 25,0 & 25,0 \\
\hline Unipersonal & 10,0 & 9,0 & 10,0 & 12,0 & 10,0 \\
\hline \multicolumn{6}{|l|}{ Promedios de integrantes } \\
\hline Menores & 0,9 & 0,9 & 0,8 & 0,8 & 0,8 \\
\hline Mayores & 2,9 & 3,0 & 2,9 & 2,8 & 2,9 \\
\hline Mujeres & 2,0 & 2,0 & 1,9 & 1,9 & 1,9 \\
\hline Hombres & 1,9 & 1,9 & 1,8 & 1,8 & 1,8 \\
\hline \multicolumn{6}{|l|}{ Localidad (\%) } \\
\hline Urbana & 78,0 & 79,0 & 79,0 & 78,0 & 78,0 \\
\hline Rural & 22,0 & 21,0 & 21,0 & 22,0 & 22,0 \\
\hline
\end{tabular}

Fuente: Elaboración propia a partir de las ENIGH (INEGI, 1994-2014). 
TABLA 2

Características sociodemográficas de los hogares con personas mayores, según localidad de residencia México - 1994-2014

\begin{tabular}{|c|c|c|c|c|c|c|}
\hline Características & 1994 & 1996 & 1998 & 2000 & 2002 & 2004 \\
\hline $\begin{array}{l}\text { Hogares en localidades urbanas } \\
\text { (con al menos una persona de } 60 \\
\text { años y más) }\end{array}$ & 14.774.050 & 15.605 .087 & 16.761.947 & 17.981 .430 & 18.759.449 & 19.809 .869 \\
\hline $\begin{array}{l}\text { Edad promedio del jefe(a) del hogar } \\
\text { Sexo de la jefatura (\%) }\end{array}$ & 44,1 & 44,1 & 45,1 & 45,7 & 46,4 & 46,3 \\
\hline Jefatura masculina & 83,0 & 82,0 & 81,0 & 80,0 & 78,0 & 76,0 \\
\hline Jefatura femenina & 17,0 & 18,0 & 19,0 & 20,0 & 22,0 & 24,0 \\
\hline \multicolumn{7}{|l|}{ Escolaridad del jefe del hogar (\%) } \\
\hline Ninguna & 12,0 & 10,0 & 9,0 & 8,0 & 10,0 & 9,0 \\
\hline Primaria & 44,0 & 43,0 & 42,0 & 40,0 & 38,0 & 38,0 \\
\hline Secundaria & 20,0 & 20,0 & 22,0 & 24,0 & 24,0 & 26,0 \\
\hline Preparatoria & 10,0 & 12,0 & 12,0 & 11,0 & 12,0 & 11,0 \\
\hline Universidad y más & 14,0 & 15,0 & 15,0 & 17,0 & 16,0 & 16,0 \\
\hline \multicolumn{7}{|l|}{ Tipo de hogar (\%) } \\
\hline Nuclear & 70,0 & 71,0 & 71,0 & 71,0 & 70,0 & 67,0 \\
\hline Ampliado o compuesto & 23,0 & 23,0 & 21,0 & 21,0 & 23,0 & 24,0 \\
\hline Unipersonal & 7,0 & 6,0 & 8,0 & 8,0 & 7,0 & 9,0 \\
\hline \multicolumn{7}{|l|}{ Promedios de integrantes } \\
\hline Menores & 3,2 & 3,2 & 3,1 & 3,0 & 3,1 & 3,0 \\
\hline Mayores & 1,2 & 1,2 & 1,1 & 1,0 & 1,0 & 1,0 \\
\hline Mujeres & 2,3 & 2,2 & 2,2 & 2,1 & 2,1 & 2,1 \\
\hline Hombres & 2,2 & 2,1 & 2,0 & 1,9 & 2,0 & 1,9 \\
\hline $\begin{array}{l}\text { Hogares en localidades rurales (con al } \\
\text { menos una persona de } 60 \text { años y más) }\end{array}$ & 4.438 .418 & 4.357 .842 & 4.864 .789 & 5.170 .126 & 5.772 .182 & 5.751 .578 \\
\hline Edad promedio del jefe(a) del hogar & 47,1 & 47,0 & 48,0 & 49,1 & 49,4 & 49,1 \\
\hline \multicolumn{7}{|l|}{ Sexo de la jefatura (\%) } \\
\hline Jefatura masculina & 89,0 & 88,0 & 86,0 & 85,0 & 85,0 & 80,0 \\
\hline Jefatura femenina & 11,0 & 12,0 & 14,0 & 15,0 & 15,0 & 20,0 \\
\hline \multicolumn{7}{|l|}{ Escolaridad del jefe del hogar (\%) } \\
\hline Ninguna & 35,0 & 27,0 & 28,0 & 28,0 & 31,0 & 21,0 \\
\hline Primaria & 55,0 & 61,0 & 60,0 & 59,0 & 54,0 & 58,0 \\
\hline Secundaria & 6,0 & 8,0 & 8,0 & 10,0 & 10,0 & 16,0 \\
\hline Preparatoria & 2,0 & 2,0 & 2,0 & 2,0 & 3,0 & 4,0 \\
\hline Universidad y más & 2,0 & 1,0 & 1,0 & 1,0 & 3,0 & 2,0 \\
\hline \multicolumn{7}{|l|}{ Tipo de hogar (\%) } \\
\hline Nuclear & 68,0 & 67,0 & 71,0 & 68,0 & 71,0 & 69,0 \\
\hline Ampliado o compuesto & 26,0 & 27,0 & 22,0 & 24,0 & 21,0 & 24,0 \\
\hline Unipersonal & 6,0 & 6,0 & 8,0 & 8,0 & 8,0 & 8,0 \\
\hline \multicolumn{7}{|l|}{ Promedios de integrantes } \\
\hline Menores & 1,7 & 1,7 & 1,5 & 1,4 & 1,2 & 1,2 \\
\hline Mayores & 3,4 & 3,4 & 3,2 & 3,2 & 3,1 & 3,1 \\
\hline Mujeres & 2,5 & 2,6 & 2,4 & 2,3 & 2,2 & 2,2 \\
\hline Hombres & 2,6 & 2,6 & 2,4 & 2,3 & 2,1 & 2,1 \\
\hline
\end{tabular}


(continuación)

\begin{tabular}{|c|c|c|c|c|c|}
\hline Características & 2006 & 2008 & 2010 & 2012 & 2014 \\
\hline $\begin{array}{l}\text { Hogares en localidades urbanas } \\
\text { (con al menos una persona de } 60 \\
\text { años y más) }\end{array}$ & 21.343 .952 & 21.903 .875 & 23.242 .996 & 24.641 .294 & 24.705 .710 \\
\hline Edad promedio del jefe(a) del hogar & 46,4 & 47,9 & 48,2 & 48,3 & 48,8 \\
\hline \multicolumn{6}{|l|}{ Sexo de la jefatura (\%) } \\
\hline Jefatura masculina & 74,0 & 74,0 & 74,0 & 74,0 & 73,0 \\
\hline Jefatura femenina & 26,0 & 26,0 & 26,0 & 26,0 & 27,0 \\
\hline \multicolumn{6}{|l|}{ Escolaridad del jefe del hogar (\%) } \\
\hline Ninguna & 7,0 & 7,0 & 7,0 & 6,0 & 5,0 \\
\hline Primaria & 35,0 & 36,0 & 34,0 & 32,0 & 29,0 \\
\hline Secundaria & 27,0 & 27,0 & 28,0 & 29,0 & 29,0 \\
\hline Preparatoria & 14,0 & 13,0 & 14,0 & 15,0 & 17,0 \\
\hline Universidad y más & 17,0 & 17,0 & 18,0 & 18,0 & 19,0 \\
\hline \multicolumn{6}{|l|}{ Tipo de hogar (\%) } \\
\hline Nuclear & 65,0 & 65,0 & 64,0 & 62,0 & 64,0 \\
\hline Ampliado o compuesto & 25,0 & 26,0 & 25,0 & 26,0 & 26,0 \\
\hline Unipersonal & 10,0 & 10,0 & 11,0 & 12,0 & 11,0 \\
\hline \multicolumn{6}{|l|}{ Promedios de integrantes } \\
\hline Menores & 3,0 & 3,0 & 3,0 & 2,9 & 2,9 \\
\hline Mayores & 0,9 & 0,9 & 0,8 & 0,8 & 0,8 \\
\hline Mujeres & 2,0 & 2,0 & 1,9 & 1,9 & 1,9 \\
\hline Hombres & 1,9 & 1,9 & 1,8 & 1,8 & 1,8 \\
\hline $\begin{array}{l}\text { Hogares en localidades rurales (con al } \\
\text { menos una persona de } 60 \text { años y más) }\end{array}$ & 6.101 .404 & 5.970 .750 & 6.313 .776 & 6.918 .085 & 6.965 .292 \\
\hline Edad promedio del jefe(a) del hogar & 49,3 & 49,3 & 48,5 & 49,8 & 48,9 \\
\hline \multicolumn{6}{|l|}{ Sexo de la jefatura (\%) } \\
\hline Jefatura masculina & 77,0 & 80,0 & 81,0 & 79,0 & 80,0 \\
\hline Jefatura femenina & 23,0 & 20,0 & 19,0 & 21,0 & 20,0 \\
\hline \multicolumn{6}{|l|}{ Escolaridad del jefe del hogar (\%) } \\
\hline Ninguna & 20,0 & 19,0 & 19,0 & 20,0 & 17,0 \\
\hline Primaria & 56,0 & 58,0 & 54,0 & 52,0 & 51,0 \\
\hline Secundaria & 17,0 & 17,0 & 19,0 & 20,0 & 23,0 \\
\hline Preparatoria & 5,0 & 4,0 & 5,0 & 6,0 & 6,0 \\
\hline Universidad y más & 2,0 & 2,0 & 3,0 & 3,0 & 3,0 \\
\hline \multicolumn{6}{|l|}{ Tipo de hogar (\%) } \\
\hline Nuclear & 68,0 & 68,0 & 68,0 & 67,0 & 69,0 \\
\hline Ampliado o compuesto & 24,0 & 24,0 & 24,0 & 23,0 & 23,0 \\
\hline Unipersonal & 8,0 & 8,0 & 8,0 & 10,0 & 8,0 \\
\hline \multicolumn{6}{|l|}{ Promedios de integrantes } \\
\hline Menores & 1,1 & 1,2 & 1,1 & 1,0 & 1,0 \\
\hline Mayores & 3,1 & 3,2 & 3,1 & 2,9 & 3,0 \\
\hline Mujeres & 2,1 & 2,2 & 2,1 & 2,0 & 2,0 \\
\hline Hombres & 2,0 & 2,1 & 2,1 & 1,9 & 2,0 \\
\hline
\end{tabular}

Fuente: Elaboración propia a partir de la ENIGH 1994-2014. 
El tamaño de localidad de residencia aparece como un factor de diferenciación socioeconómica. Así, se reconoce que una de las mayores diferencias en la población aparece en el nivel de urbanización o de ruralidad (HAM, 2003). Al analizar la localidad de residencia de los hogares, la Gráfica 1 ilustra las marcadas diferencias en la distribución por edades de los jefes(as) de hogar. Si se agregan los tres últimos grupos de edad se observan mayores participaciones de las edades avanzadas en los hogares rurales. Por ejemplo, en 1994, el $24,2 \%$ de los hogares rurales estaba dirigido por una persona de sesenta años y más, mientras que en los hogares urbanos esta cifra era de 18,4\%. En 2014, estos porcentajes fueron $26,7 \%$ y $24,8 \%$ respectivamente.

\section{GRÁFICA 1}

Distribución de los jefes(as) de los hogares, por grupos de edad, según localidad de residencia México - 1994-2014
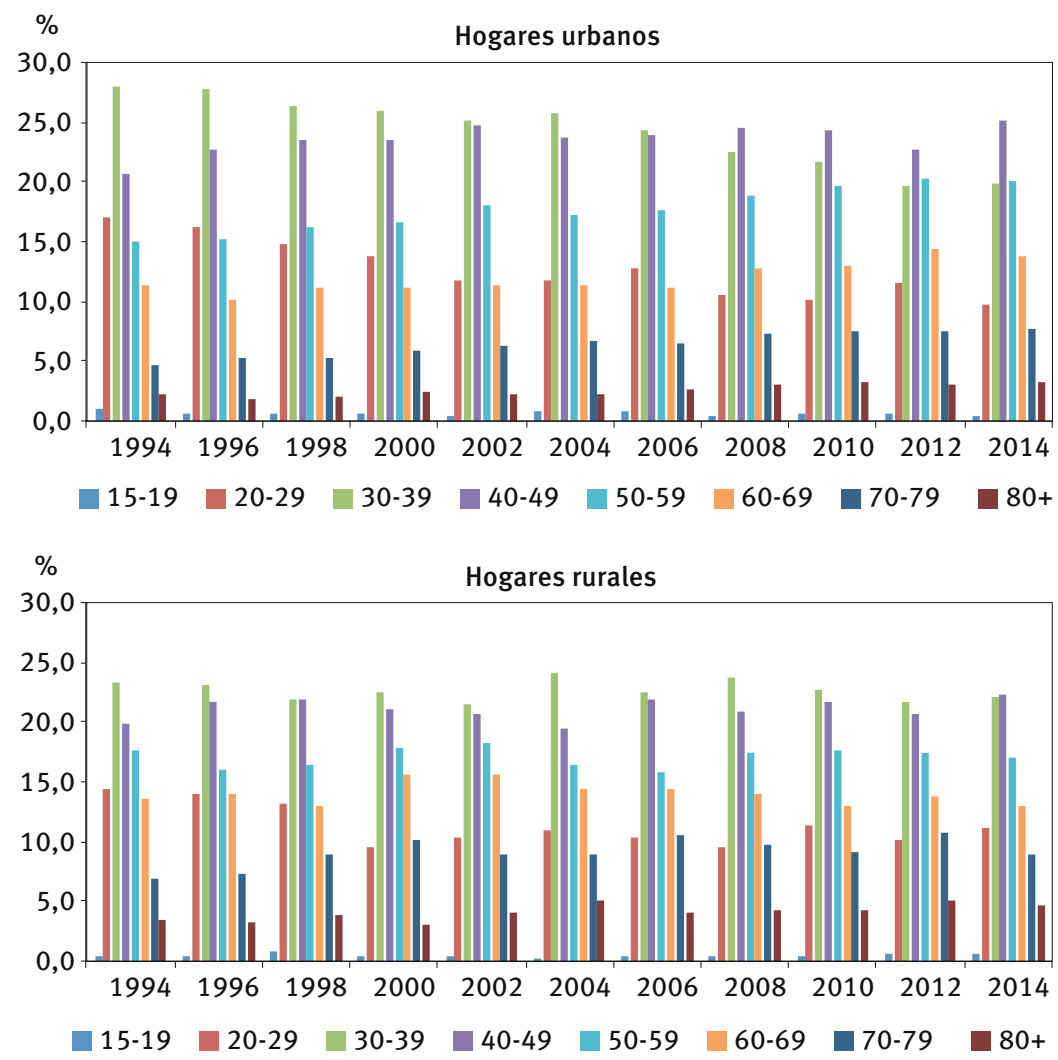

Fuente: Elaboración propia a partir de la ENIGH 1994-2014.

Una variable que es central en el estudio del ahorro es el ingreso. La principal fuente de ingresos en los hogares son los estipendios derivados del trabajo. La Gráfica 2 muestra que $72,6 \%$ de los ingresos en los hogares urbanos provienen del trabajo, ya sea remunerado o independiente, y que en los rurales esta cifra es $65,7 \%$, mientras que las transferencias tienen una menor participación, aunque más notoria en los hogares rurales. Cabe mencionar 
que el ingreso mensual per cápita es significativamente distinto según localidad. Por ejemplo, la remuneración media por trabajo en las localidades rurales es de 913 pesos mexicanos y en las urbanas, de 2.590 pesos. Por su parte, para las transferencias -que incluyen pensiones contributivas y no contributivas, remesas y apoyo de otros hogares-, estas cifras son 323 y 478 pesos, y aunque es más común que en las zonas rurales predominen los apoyos gubernamentales, sus montos son muy bajos. En 2013, el Programa de Pensión para Adultos Mayores modificó sus parámetros, al considerar la entrega de apoyos económicos y de protección social para toda la población de 65 y más años que no recibía ingresos por concepto de pago de jubilación o pensión de tipo contributivo, pero no es hasta 2019 que se establece la pensión universal no contributiva (Pensión para el Bienestar de las Personas Adultas Mayores), que brinda apoyo a las personas mayores de 68 años (y en las zonas indígenas a partir de los 65 años). Por último, los hogares que reciben apoyo de otros hogares o remesas conforman menos del $10 \%$.

Las transferencias, en especial las derivadas de las pensiones, constituyen una variable que influye sobre las posibilidades de ahorro. Como parte de las futuras líneas de investigación está pendiente incorporar un tratamiento diferenciado para estas fuentes de ingreso. David Demery y Nigel Duck (2004) señalan la relevancia de asignar un tratamiento adecuado de los ingresos por pensiones.

GRÁFICA 2

Distribución de los ingresos de los hogares, según fuente y localidad de residencia México - 2014

$\%$

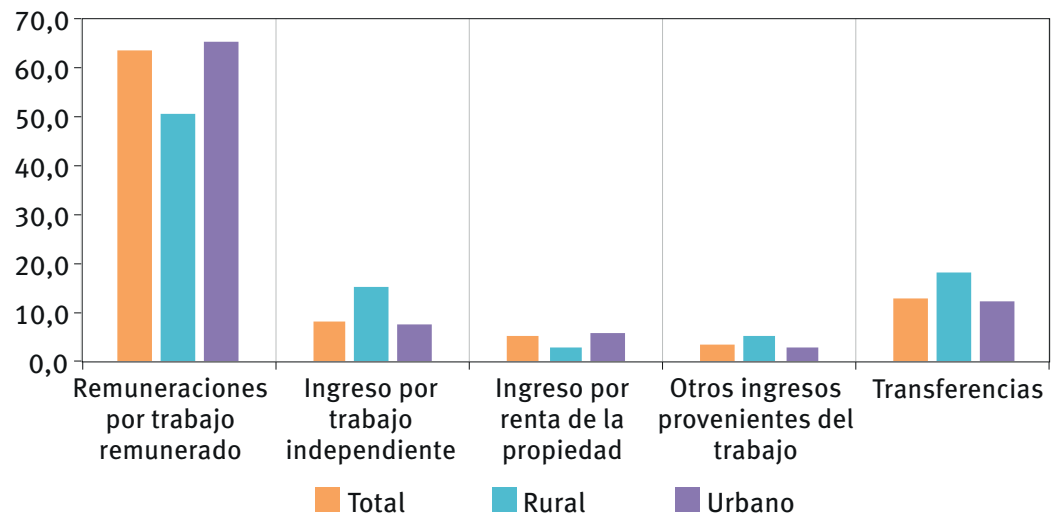

Fuente: Elaboración propia a partir de la ENIGH 2014.

\section{Metodología}

\section{Fuente de información}

Los datos utilizados en este documento fueron tomados de la ENIGH en sus levantamientos bienales desde 1994 hasta 2014, por lo que se trabajó con un total de once encuestas. 
Debido al esquema de muestreo de la encuesta, estratificado, bietápico y por conglomerados, en el que la unidad de observación es el hogar y la unidad última de selección es la vivienda, se cuenta con representatividad nacional y para las áreas rurales (localidades con menos de 2.500 habitantes) y urbanas (localidades de 2.500 y más habitantes).

La ENIGH incluye información estadística detallada sobre el monto, la procedencia y la distribución de los ingresos y gastos de los hogares, además de las características sociodemográficas y ocupacionales de la población y las características de equipamiento del hogar y la infraestructura de la vivienda. De ellas, las variables que se utilizan en esta investigación son:

- ingreso corriente monetario: suma de los ingresos por trabajo, negocios, rentas y transferencias;

- gasto corriente monetario: suma de los desembolsos regulares en bienes y servicios para consumo, como alimentos, vestido y calzado, vivienda, limpieza, salud, transporte y educación, entre otros;

- características sociodemográficas de los hogares: incluye características del jefe(a) del hogar, como sexo, edad, parentesco, escolaridad y acceso a la salud, y de aquellas relacionadas con la configuración del hogar, como tamaño del hogar, integrantes ocupados, personas de entre 12 y 64 años de edad y personas de 65 años y más.

\section{Construcción del panel sintético}

El panel sintético es una técnica propuesta por Martin Browning, Angus Deaton y Margaret Irish (1985) que permite una aproximación al comportamiento dinámico del ingreso, del consumo y el ahorro a partir del uso de encuestas transversales. Para ello es necesario construir cohortes sintéticas con base en un criterio fijo y para un intervalo constante, como el año de nacimiento. En esta investigación se utilizó el año de nacimiento del jefe(a) del hogar. Así, la primera cohorte incluye a los jefes(as) cuya edad se encontraba entre los 72 y los 76 años con respecto a la primera encuesta en la que se recolectó la información, que data de 1994. Así, este grupo de individuos pertenece a una generación específica, la de los jefes(as) de hogar nacidos(as) entre 1918 y 1922 y que para la encuesta de 1996 tenían entre 74 y 78 años. En la siguiente encuesta, la de 1998, esta misma generación tenía entre 76 y 80 años de edad, y así sucesivamente para cada año de la encuesta, hasta llegar a la última, en 2014, cuando la cohorte se encuentra en el rango de edades de 92 a 96 años (Tabla 3). 
TABLA 3

Construcción de las cohortes sintéticas

\begin{tabular}{|c|c|c|c|c|c|c|c|c|c|c|c|}
\hline \multirow{3}{*}{ Años } & \multicolumn{11}{|c|}{ Cohortes } \\
\hline & 1 & 2 & 3 & 4 & 5 & 6 & 7 & 8 & 9 & 10 & 11 \\
\hline & $\begin{array}{l}1918- \\
1922\end{array}$ & $\begin{array}{c}1923- \\
1927\end{array}$ & $\begin{array}{c}1928- \\
1932\end{array}$ & $\begin{array}{c}1933- \\
1937\end{array}$ & $\begin{array}{c}1938- \\
1942\end{array}$ & $\begin{array}{c}1943- \\
1947\end{array}$ & $\begin{array}{c}1948- \\
1952\end{array}$ & $\begin{array}{c}1953- \\
1957\end{array}$ & $\begin{array}{c}1958- \\
1962\end{array}$ & $\begin{array}{c}1963- \\
1967\end{array}$ & $\begin{array}{c}1968- \\
1972\end{array}$ \\
\hline 1994 & $72-76$ & $67-71$ & $62-66$ & $57-61$ & $52-56$ & $47-51$ & $42-46$ & $37-41$ & $32-36$ & $27-31$ & $22-26$ \\
\hline 1996 & $74-78$ & $69-73$ & $64-68$ & $59-63$ & $54-58$ & $49-53$ & $44-48$ & $39-43$ & $34-38$ & $29-33$ & $24-28$ \\
\hline 1998 & $76-80$ & $71-75$ & $66-70$ & $61-65$ & $56-60$ & $51-55$ & $46-50$ & $41-45$ & $36-40$ & $31-35$ & $26-30$ \\
\hline 2000 & $78-82$ & $73-77$ & $68-72$ & $63-67$ & $58-62$ & $53-57$ & $48-52$ & $43-47$ & $38-42$ & $33-37$ & $28-32$ \\
\hline 2002 & $80-84$ & $75-79$ & $70-74$ & $65-69$ & $60-64$ & $55-59$ & $50-54$ & $45-49$ & $40-44$ & $35-39$ & $30-34$ \\
\hline 2004 & $82-86$ & $77-81$ & $72-76$ & $67-71$ & $62-66$ & $57-61$ & $52-56$ & $47-51$ & $42-46$ & $37-41$ & $32-36$ \\
\hline 2006 & $84-88$ & $79-83$ & $74-78$ & $69-73$ & $64-68$ & $59-63$ & $54-58$ & 49-53 & $44-48$ & $39-43$ & $34-38$ \\
\hline 2008 & $86-90$ & $81-85$ & $76-80$ & $71-75$ & $66-70$ & $61-65$ & $56-60$ & $51-55$ & $46-50$ & $41-45$ & $36-40$ \\
\hline 2010 & $88-92$ & $83-87$ & $78-82$ & $73-77$ & $68-72$ & $63-67$ & $58-62$ & $53-57$ & $48-52$ & $43-47$ & $38-42$ \\
\hline 2012 & $90-94$ & $85-89$ & $80-84$ & $75-79$ & $70-74$ & $65-69$ & $60-64$ & $55-59$ & $50-54$ & $45-49$ & $40-44$ \\
\hline 2014 & $92-96$ & $87-90$ & $82-86$ & $77-81$ & $72-76$ & $67-71$ & $62-66$ & $57-61$ & $52-56$ & $47-51$ & $42-46$ \\
\hline
\end{tabular}

Fuente: Elaboración propia a partir de la ENIGH 1994-2014.

La segunda cohorte corresponde a la generación de 1923-1927, que en el año 1994 tenía entre 67 y 71 años, para la encuesta de 1996, entre 69 y 73 años, y así sucesivamente hasta 2014, cuando tenían entre 87 y 91 años. Este proceso se repite para las once cohortes.

Cabe mencionar que la técnica de panel sintético presenta limitaciones, entre las que la principal es que en el tiempo no se sigue a las mismas personas que comenzaron a relevarse, de modo que las historias de vida no están disponibles para su inclusión en el modelo. A ello se agrega la presencia de fenómenos demográficos como la emigración, la inmigración, los nacimientos y las muertes, que modifican la estructura de la población de un año a otro. Además pueden formarse nuevos hogares o desintegrarse (DEATON; PAXSON, 1998). ${ }^{1}$ Sin embargo, esto implica también ventajas importantes, ya que, a diferencia de los datos de panel, no existe pérdida de observaciones en el tiempo (attrition). ${ }^{2} \mathrm{~A}$ su vez, el número de observaciones es mayor tanto en lo que respecta al número de personas (hogares) como al período que abarcan (VERBEEK, 2008). Este trabajo parte de considerar la riqueza del análisis de las cohortes sintéticas como la diversidad derivada de tener varias cohortes vivas al mismo tiempo y de la posibilidad de analizar el ahorro de manera dinámica. Como señala Angus Deaton (1997), las variables más importantes que dan cuenta de los niveles de vida, como el ingreso y el consumo, tienen fuertes componentes relacionados con la edad a lo largo del ciclo de vida.

\footnotetext{
${ }^{1}$ Deaton (1997) señala que siempre que la cohorte no esté tan envejecida como para que sus miembros estén falleciendo en cantidades significativas, se pueden utilizar encuestas transversales para seguir a cada cohorte a lo largo del tiempo. ${ }^{2}$ La pérdida de observaciones puede generar problemas en la representatividad de la muestra a medida que avanza el tiempo. Esta pérdida de observaciones puede ser causada por rechazo a la entrevista, muerte o cambio de domicilio.
} 


\section{Modelo econométrico}

La estimación de los perfiles por edades a partir del modelo econométrico requiere tener en cuenta la presencia simultánea del efecto por cohorte, edad y período. Andrew Bell y Kelvyn Jones (2013) presentan una extensa revisión bibliográfica sobre las soluciones al problema de identificación por multicolinealidad perfecta, y concluyen que ningún modelo es capaz de resolver el problema de identificación porque este es inherente a los procesos que se están modelando. Sin embargo, también señalan que analizar por separado los tres efectos es importante para las investigaciones socioeconómicas. Se requiere modelar la ecuación sobre supuestos acordes con la teoría.

Una de las descomposiciones estadísticas más utilizadas en el análisis del ahorro es la normalización propuesta por Angus Deaton (1997). ${ }^{3}$ Al conocer el año de la encuesta y el año de nacimiento de la cohorte se puede obtener la edad, por lo que la ecuación resultará en una identidad. El mismo Angus Deaton (1997) propone agregar una tendencia temporal a las variables dicotómicas de las edades y restar la tendencia temporal de las variables dicotómicas de las cohortes y los períodos para compensar los efectos. La normalización propuesta por el autor consiste en estimar el ahorro a partir de los efectos de edad y cohorte y utilizar el efecto período para capturar los efectos del ciclo económico, cuyo promedio suma cero en el largo plazo. Una normalización de este tipo implica que el efecto período sea ortogonal a la tendencia temporal.

Al generar variables dicotómicas en el año de cada encuesta se evita la correlación tendencial y, por ende, la multicolinealidad, por lo que las variables dicotómicas latentes dan origen a la siguiente ecuación:

$d_{t}=d_{t}-\left[(t-1) d_{2}-(t-2) d_{1}\right]$

Donde: $d_{t}$ es una variable dicotómica relacionada con el año y donde $t$ toma valores de 1 o 0 . El valor de 1 se especifica para la encuesta utilizada para ese momento específico, es decir, si se refiere a la ENIGH de 1994, entonces $t=1$, y así sucesivamente para cada año de la encuesta.

Después de aplicar la corrección de la multicolinealidad, con la implementación de la ecuación (1) se procede a estimar el modelo semiparamétrico lineal en dos etapas. Se utiliza el modelo propuesto por Paul Speckman (1988) y retomado por Jesús FernándezVillaverde y Dirk Krueger (2007) que combina estimadores parámetricos en su primera etapa y estimadores no paramétricos, mediante una función Kernel, en su segunda etapa: $S_{i t}=\beta_{i}$ Cohorte $_{i}+\beta_{t}$ tiempo $_{t}+m(\text { edad })_{i t}+\varepsilon_{i t}$

Donde: $S_{i t}$ representa el ahorro ${ }^{4}$ (ingreso o consumo) del hogar en la cohorte $i$ y el año $t$. El subíndice $i$ hace referencia a la parte de la cohorte y el subíndice $t$ al año en cuestión, que corresponde a la encuesta. La $\beta_{t}$ y la Cohorte $_{i}$ son variables dicotómicas que para cada

\footnotetext{
${ }^{3}$ Las investigaciones que analizan el ahorro a lo largo del ciclo vital en México retoman la propuesta de Deaton (1997), por ejemplo: Fuentes y Villagómez (2001), Nava (2015) y Ceballos (2018).

${ }^{4}$ El ahorro se obtiene como la diferencia entre el ingreso y el consumo (SZÉKELY, 1998).
} 
año de la encuesta se estiman de forma paramétrica. Para la función $m(e d a d)_{i t}$ corresponde la parte no paramétrica y se estima mediante polinomios locales (función Kernel), por lo que para una edad específica $\left(x_{0}\right)$ se tendrá una aproximación puntual, mientras que el residual $\varepsilon_{i t}$ es aleatorio e independiente (CEBALLOS, 2018).

Al agregar la función $m\left(x_{0}\right)$, que corresponde a la parte no lineal, se estima mediante la ecuación de $S_{j}=m\left(x_{0}\right)+\varepsilon_{j}$, un punto específico correspondiente a la edad, para generar la siguiente ecuación:

$\operatorname{argmin}\left(x_{0}\right)=\sum_{t=1}^{N}\left\{Y_{i}-\sum_{j=0}^{p} \beta_{j}\left(X_{i}-x_{0}\right)^{j}\right\}^{2} K\left(X_{i}-x_{0}\right)$

Donde: $K$ es una función Kernel que asigna mayor peso a los hogares cuya edad del jefe tiene valor cercano a $\left(x_{0}\right)$, por lo que se tendrá una estimación aproximada con respecto a la función de la edad y donde dicha función $m\left(x_{0}\right)$ resulta sensible a las variaciones de los patrones de ahorro (CEBALLOS, 2018). De acuerdo con Roberto Gutiérrez, Jean-Marie Linhart y Jeffrey Pitblado (2003) para mantener la localidad $m$ ( ), es decir las edades de los jefes de hogar, se introduce una función de densidad de probabilidad para controlar el grado de localidad, para que al momento de tratar los datos se puedan ponderar los datos casi de manera equivalente a una regresión lineal ponderada. De esta manera, es necesario introducir un polinomio local para estimar, cuando $m\left(x_{0}\right)$ y utilizar la regresión ponderada tomando como parámetro $\left(x_{0}\right)$.

La segunda corresponde a la parte no paramétrica, los efectos no lineales de la edad del jefe(a) del hogar sobre el ahorro. Se han incorporado las variables dicotómicas para controlar los efectos cohorte y tiempo, que hacen referencia a las encuestas. Por consiguiente, se puede despejar de la ecuación anterior los $\hat{u}_{i t}$ estimados de la regresión generando $\hat{u}_{i t}=S_{i t}-\hat{\beta}_{i}$ Cohorte $_{i}-\hat{\beta}_{t}$ tiemp $_{t}$ para plantear la ecuación (4), que corresponde a la etapa no paramétrica:

$\hat{u}_{i t}=m\left(\operatorname{edad}_{i t}\right)+v_{i t}$

Ceballos (2018) plantea que si bien hay pérdida de eficiencia de una estimación en dos etapas, como la anterior, bien vale el esfuerzo de capturar las variaciones que se tienen en los perfiles de las variables de interés por las variaciones presentadas de la función $m(e d a d)$. Lo anterior permite también la comparabilidad de los datos en los hogares urbanos/rurales.

Cabe mencionar que, con el objetivo de controlar el efecto de la composición y el tamaño del hogar sobre los perfiles estimados, se ajustaron los datos con escalas de equivalencia (FERNÁNDEZ-VILLAVERDE; KRUEGER, 2007). Se utilizó la escala elaborada por la Organización para la Cooperación y el Desarrollo Económicos actualizada, que consiste en aplicar la raíz cuadrada de la variable número de integrantes en el hogar (OCDE, 2019). Además, se deflactaron los datos sobre montos de ingreso y consumo con base en el Índice Nacional de Precios al Consumidor (INPC), base 2014. 


\section{Análisis del ahorro de los hogares}

La Gráfica 3 ilustra los perfiles de ingreso, gasto en consumo y ahorro de los hogares rurales y urbanos, estimados a partir del modelo semiparamétrico lineal en dos etapas. Se aprecia que el ingreso describe un perfil de $U$ invertida, como lo plantea la HCV, aunque con marcadas diferencias en términos de montos, entre las que resaltan mayores niveles de ingreso en los hogares urbanos. Incluso cuando los jefes(as) comienzan a recibir ingresos, en las zonas rurales comienzan con marcadas desventajas. El consumo sigue un perfil muy similar al del ingreso, es decir que existe una alta correlación entre ambas variables, lo que lleva a que los hogares rurales presenten niveles de consumo significativamente menores: el ahorro sigue un perfil distinto a la HCV. En ambos hogares, el ahorro comienza poco antes de los cuarenta años y se mantiene en las edades avanzadas. Estos resultados coinciden con los hallazgos de Alejandro Villagómez y Andrés Zamudio (1997) y Fernando Solís y Alejandro Villagómez (1999). En el ámbito internacional, Joaquín Alegre y Llorenç Pou (2008) también encuentran para el caso de España que las tasas de ahorro presentan valores positivos en las edades avanzadas y un perfil continuamente creciente.

Una diferencia importante es la reducción del ahorro que se presenta en los hogares rurales con jefaturas de hogar de sesenta años para después volver a aumentar. Es posible que este ligero repunte del ahorro se atribuya a un motivo precautorio, como plantean Fuentes y Villagómez (2001).

\section{GRÁFICA 3}

Perfiles de ingreso, gasto en consumo y ahorro de los hogares rurales y urbanos, según edad de los jefes de los hogares México - 1994-2014

Hogares rurales

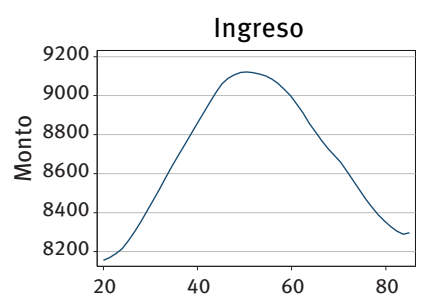

Edad de los jefes(as) de los hogares

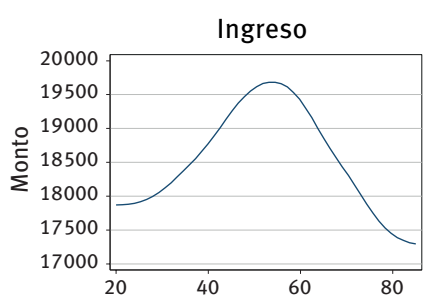

Edad de los jefes(as) de los hogares

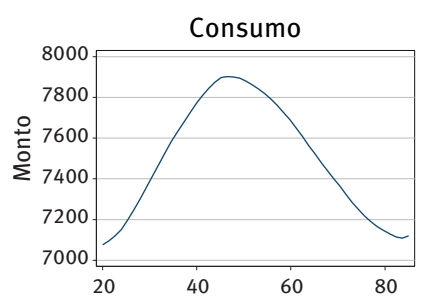

Edad de los jefes(as) de los hogares

Hogares urbanos

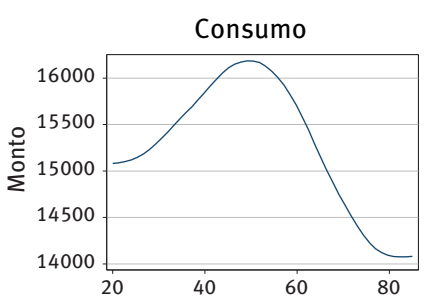

Edad de los jefes(as) de los hogares

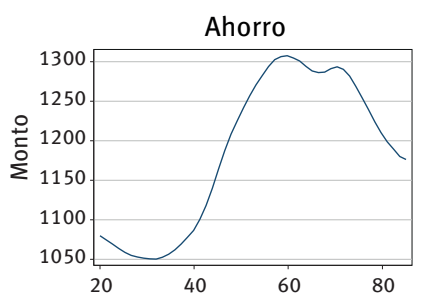

Edad de los jefes(as) de los hogares

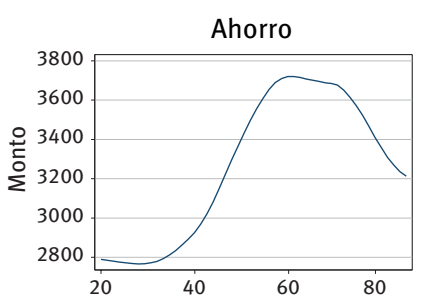

Edad de los jefes(as) de los hogares

Fuente: Elaboración propia a partir de la ENIGH 1994-2014.

Nota: Montos trimestrales $(2014=100)$ ajustados por escalas de equivalencia OCDE actualizadas. 
Estos perfiles permiten una aproximación sobre el perfil de las variables según localidad de residencia. La Gráfica 4 ilustra los perfiles de los hogares rurales según condición de acceso a la salud, por parte de las personas mayores. Se ha agregado esta variable de control, ya que se reconoce que en las edades avanzadas una variable que modifica significativamente las condiciones socioeconómicas es la condición de salud. Es en las edades avanzadas cuando son más notorias las consecuencias de la morbilidad y la incapacidad sobre la salud (HAM, 2003). Además de reducir las posibilidades de participar en el mercado laboral, las enfermedades crónico-degenerativas pueden plantear altos gastos en salud. Se considera que el acceso a los servicios de salud otorga una oportunidad de mantener o destinar los ahorros acumulados a otras necesidades. A ello se agregan los motivos de ahorro, ya que las personas mayores tienen más incentivos para ahorrar para la seguridad de la vejez (GE; YANG; ZHANG, 2018).

Entre los hogares rurales, con personas mayores, pero que tienen protección de salud, se aprecia un perfil de ahorro que comienza en la cuarta década y se extiende luego de cumplidos los sesenta años. Un resultado alarmante es el de las desventajosas condiciones de los hogares rurales, con personas mayores y sin acceso a la seguridad social. Los ingresos que registran en las edades activas son muy bajos: de hecho, disminuyen en las edades intermedias. El ahorro describe una forma de V, que puede indicar los efectos negativos de la falta de acceso a instituciones de salud, causa por la que los hogares puedan no haber tenido la posibilidad de ahorrar e incluso hayan utilizado los ahorros generados, además de abastecer los requerimientos de las personas mayores.

\section{GRÁFICA 4}

Perfiles de los hogares rurales, según condición de acceso a la salud por parte de las personas mayores México - 1994-2014

Hogares rurales con al menos una persona mayor y con acceso a salud

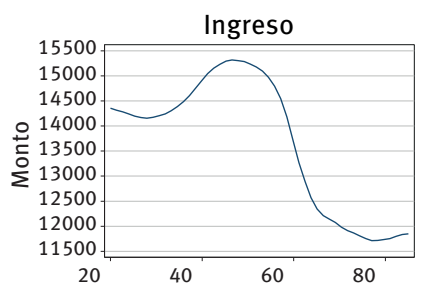

Edad de los jefes(as) de los hogares

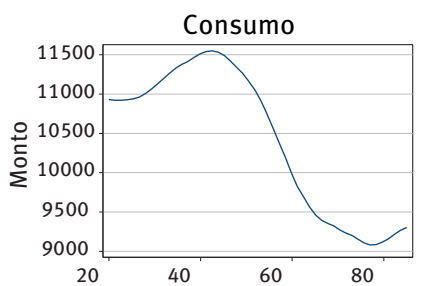

Edad de los jefes(as) de los hogares

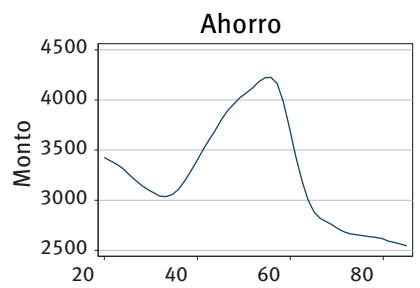

Edad de los jefes(as) de los hogares

Hogares rurales con al menos una persona mayor y sin acceso a salud

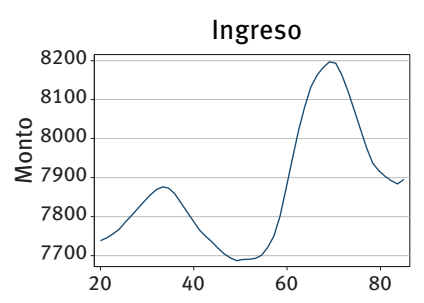

Edad de los jefes(as) de los hogares

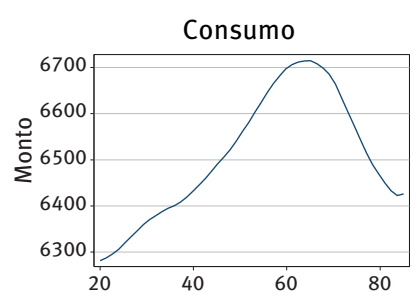

Edad de los jefes(as) de los hogares

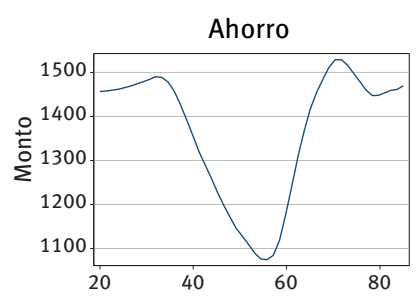

Edad de los jefes(as) de los hogares

Fuente: Elaboración propia a partir de la ENIGH 1994-2014.

Nota: Montos trimestrales $(2014=100)$ ajustados por escalas de equivalencia OCDE actualizadas. 
En relación con los perfiles de los hogares urbanos, con personas mayores y acceso a servicios de salud, tanto el ingreso como el consumo muestran una correlación, explicada por un ingreso a la baja, pero también montos de consumo más altos (Gráfica 5). Se aprecia, en los tres perfiles, una meseta entre las edades de cuarenta a sesenta, reflejando estabilidad en los tres perfiles. Por su parte, en los hogares sin acceso el perfil de ahorro, en etapas iniciales del ciclo de vida, presentó una tendencia negativa hasta los cuarenta años, para luego revertir esta tendencia generando una forma que se aproxima a una $U$ invertida. Es posible que uno de los motivos para generar un ahorro sea la incertidumbre y sea reflejo de no tener acceso a la salud.

Los resultados muestran un perfil no esperado, que puede deberse a las características propias de estos hogares. Una hipótesis tentativa al respecto se relaciona con las características de inserción laboral, ya que es probable que se logre el acceso a los servicios de salud, derivado de la participación en actividades económicas específicas que brinda esta protección, pero donde los ingresos son más bajos.

\section{GRÁFICA 5}

Perfiles de los hogares urbanos, según condición de acceso a la salud por parte de las personas mayores México - 1994-2014

Hogares urbanos con al menos una persona mayor y con acceso a la salud

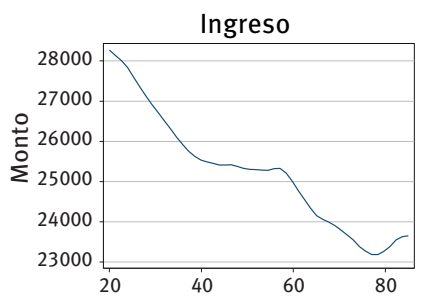

Edad de los jefes(as) de los hogares

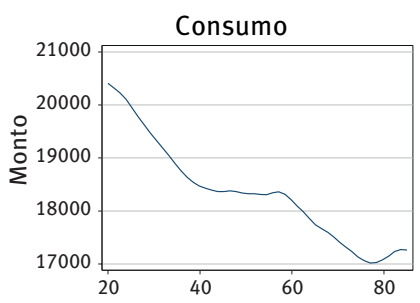

Edad de los jefes(as) de los hogares

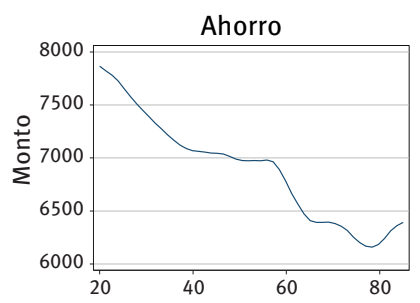

Edad de los jefes(as) de los hogares

Hogares urbanos con al menos una persona mayor y sin acceso a la salud

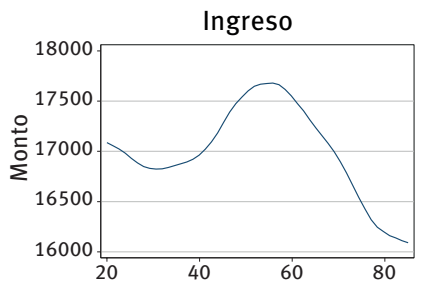

Edad de los jefes(as) de los hogares

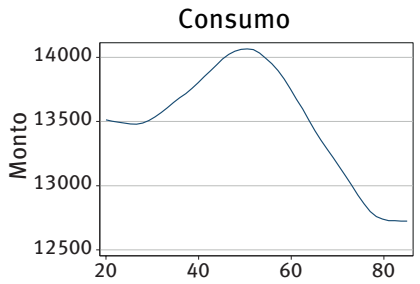

Edad de los jefes(as) de los hogares

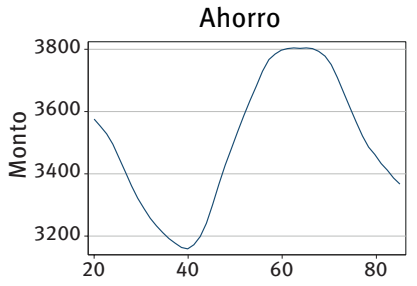

Edad de los jefes(as) de los hogares

Fuente: Elaboración propia a partir de las ENIGH 1994-2014.

Nota: Montos trimestrales $(2014=100)$ ajustados por escalas de equivalencia OCDE actualizadas. 


\section{Conclusiones}

Este artículo se encargó de analizar las pautas de ingreso, consumo y ahorro de los hogares rurales y urbanos y encontró sustanciales diferencias. Primero, en un nivel general del análisis hecho, la diferencia de ahorro fue 2,9 veces mayor en los hogares urbanos respecto a los rurales. Esta variación se observó, según la Gráfica 3, en los hogares rurales, que tuvieron un ingreso máximo aproximado de 9.200 pesos trimestrales, mientras que los hogares urbanos registraron un ingreso máximo cercano a 20.000 pesos trimestrales, una diferencia 2,1 veces mayor en los ingresos urbanos con respecto a los rurales.

En el siguiente nivel de análisis se introdujeron en los hogares rurales y urbanos las variables que pudieran incidir en el nivel de ahorro: una persona adulta mayor, como uno de sus miembros del hogar, y el acceso a salud. Los hogares rurales con acceso a salud lograron generar cierto nivel de ahorro, pero en los hogares que carecían de acceso a servicios médicos el ahorro no lograba conformar una $U$ invertida. La posible explicación para ello es que estos hogares tenían que utilizar sus recursos para poder cubrir sus necesidades en salud y suavizaban así su consumo. Los hogares urbanos que tienen al menos una persona mayor y con acceso a salud presentan una correlación entre el ingreso y el consumo: sus comportamientos guardan similitud provocando que los niveles de ahorro caigan desde edades muy tempranas. En contraposición, en los hogares urbanos que tienen al menos una persona mayor, pero sin acceso a la salud, logra conformarse la U invertida, aunque llama la atención que sea entre los cuarenta y los setenta años, lo que podría ser indicio de querer cubrir sus necesidades de bienes y servicios médicos.

El acceso salud que se otorga a los trabajadores suele ser un derecho que se vincula con un empleo formal y que funciona como un mecanismo redistributivo del ingreso, ya que brindaba protección y bienestar a las familias. Dentro de estas prestaciones, el acceso a salud tenía como objetivo garantizar asistencia médica y seguridad en el ingreso y ahorro ante contingencias no previstas, como enfermedades, riesgos en el trabajo y vejez. La distribución de estas prestaciones no suele ser equitativo, ya que las localidades urbanas suelen ser las más beneficiadas por la concentración de empleo formal, que contribuye al acceso a la salud y por tanto, a asistencia médica en la vejez. Por su parte, los hogares rurales tienen una desventaja significativa en tanto cubrir sus necesidades médicas con su ingreso profundiza la desigualdad económica y social entre lo urbano y lo rural. En ese sentido, es de vital importancia la correcta implementación de políticas públicas en materia laboral, acceso a la salud y condiciones de vida generales, que permitan cerrar las brechas de las desigualdades rurales. 


\section{Referencias}

ALEGRE, J.; POU, L. L. El consumo y la tasa de ahorro privados de los hogares españoles: una descomposición de los efectos edad y cohorte. Investigaciones Económicas, v. 32, n. 1, p. 87121, 2008. Disponible en: https://www.redalyc.org/pdf/173/17332104.pdf.

ALWIN, D.; MCCAMMON, R. Generations, cohorts, and social change. In: MORTIMER J. T.; SHANAHAN, M. J. (ed.). Handbook of the life course. Springer, 2003. p. 23-49.

ANDO, A.; MODIGLIANI, F. The «life cycle» hypothesis of saving: aggregate implications and tests. The American Economic Review, v. 53, n. 1, p. 55-84, 1963.

ATTANASIO, O. P.; SÉKELY, M. Ahorro de los hogares y distribución del ingreso en México. Economía Mexicana, v. 8, n. 2, p. 267-338, 1999. Disponible en: http://repositorio-digital.cide. edu/handle/11651/4190.

BELL, A.; JONES, K. Another 'futile quest'? A simulation study of yang and land's hierarchical age-period-cohort model. Demographic Research, v. 30, p. 333-360, 2014. Disponible en: https:// www.jstor.org/stable/26348202?seq=1\#metadata_info_tab_contents.

BÖRSCH-SUPAN, A.; STAHL, K. Life cycle savings and consumption constraints: theory, empirical evidence, and fiscal implications. Journal of Population Economics, v. 4, n. 3, p. 233-55, 1991.

BÖRSCH-SUPAN, A. Saving and consumption patterns of the elderly: the German case. Journal of Population Economics, v. 5, n. 4, p. 289-303, 1992.

BROWNING, M.; DEATON, A.; IRISH, M. A profitable approach to labor supply and commodity demands over the life-cycle. Econometrica, v. 53, n. 3, p. 503-544, 1985.

CAMPOS, R.; MELÉNDEZ, Á. Una estimación semiparamétrica de las pautas de consumo e ingreso a lo largo del ciclo de vida para México. El Trimestre Económico, v. 80, n. 320, p. 805-840, 2013.

CEBALLOS, O. Perfiles de ahorro y pago de deuda en el ciclo de vida de los hogares mexicanos. El Trimestre Económico, v. 85, n. 338, p. 311-339, 2018. Disponible en: http://www.scielo.org. $\mathrm{mx} /$ scielo.php?pid=S2448-718X2018000200311\&script=sci_abstract\&tlng=pt.

DEATON, A. Measuring poverty in a growing world (or measuring growth in a poor world). The Review of Economics and Statistics, v. 87, n. 1, p. 1-19, 2005.

DEATON, A. The analysis of household surveys: a microeconometric approach to development policy. Washington, DC: World Bank Group, 1997. Disponible en: http://documents.worldbank. org/curated/en/593871468777303124/The-Analysis-of-Household-Surveys-A-MicroeconometricApproach-to-Development-Policy. Acceso el: 8 ene. 2021.

DEATON, A.; PAXSON, C. Saving and growth: another look at the cohort evidence. Research Program in Development Studies, n. 225, p. 1-32, 1998.

DEMERY, D.; DUCK, N. Savings-age profiles in the UK. Journal of Population Economics, v. 19, n. 3, p. 521-541, 2006.

FERNÁNDEZ-VILLAVERDE, J.; KRUEGER, D. Consumption over the life cycle: facts from consumer expenditure survey data. Review of Economics and Statistics, v. 89, n. 3, p. 552-565, 2007. Disponible en: https://direct.mit.edu/rest/article/89/3/552/57699/Consumption-over-theLife-Cycle-Facts-from

FUENTES, R.; VILLAGÓMEZ, A. El ahorro en los hogares de bajos ingresos en México. Un análisis por cohortes. El Trimestre Económico, v. 68, n. 1, p. 109-133, 2001.

GE, S.; YANG, D. T.; ZHANG, J. Population policies, demographic structural changes, and the Chinese household saving puzzle. European Economic Review, v. 101, p. 181-209, 2018. 
GORDILLO, G.; PLASSOT, T. Transformaciones de los ingresos de los hogares mexicanos (19922018). Economía UNAM, v. 16, n. 48, p. 19-54, 2019. Disponible en: http://www.scielo.org.mx/ scielo.php?pid=S1665-952X2019000300019\&script=sci_arttext.

GUTIERREZ, R.; LINHART, J.; PITBLADO, J. From the help desk: local polynomial regression and Stata plugins. Stata Journal, v. 3, n. 4, p. 412-419, 2003.

INEGI - Instituto Nacional de Estadística y Geografía. Encuesta Nacional de Ingresos y Gastos de los Hogares (ENIGH) 1994. México, 1994. Disponible en: https://www.inegi.org.mx/programas/ enigh/tradicional/1994/. Acceso el: 9 ene. 2021.

INEGI - Instituto Nacional de Estadística y Geografía. Encuesta Nacional de Ingresos y Gastos de los Hogares (ENIGH) 1996. México, 1996. Disponible en: https://www.inegi.org.mx/programas/ enigh/tradicional/1996/. Acceso el: 9 ene. 2021.

INEGI - Instituto Nacional de Estadística y Geografía. Encuesta Nacional de Ingresos y Gastos de los Hogares (ENIGH) 1998. México, 1998. Disponible en: https://www.inegi.org.mx/programas/ enigh/tradicional/1998/. Acceso el: 9 ene. 2021.

INEGI - Instituto Nacional de Estadística y Geografía. Encuesta Nacional de Ingresos y Gastos de los Hogares (ENIGH) 2000. México, 2000. Disponible en: https://www.inegi.org.mx/programas/ enigh/tradicional/2000/. Acceso el: 9 ene. 2021.

INEGI - Instituto Nacional de Estadística y Geografía. Encuesta Nacional de Ingresos y Gastos de los Hogares (ENIGH) 2002. México, 2002. Disponible en: https://www.inegi.org.mx/programas/ enigh/tradicional/2002/. Acceso el: 9 ene. 2021.

INEGI - Instituto Nacional de Estadística y Geografía. Encuesta Nacional de Ingresos y Gastos de los Hogares (ENIGH) 2004. México, 2004. Disponible en: https://www.inegi.org.mx/programas/ enigh/tradicional/2004/. Acceso el: 9 ene. 2021.

INEGI - Instituto Nacional de Estadística y Geografía. Encuesta Nacional de Ingresos y Gastos de los Hogares (ENIGH) 2006. México, 2006. Disponible en: https://www.inegi.org.mx/programas/ enigh/tradicional/2006/. Acceso el: 9 ene. 2021.

INEGI - Instituto Nacional de Estadística y Geografía. Encuesta Nacional de Ingresos y Gastos de los Hogares (ENIGH) 2008. México, 2008. Disponible en: https://www.inegi.org.mx/programas/ enigh/tradicional/2008/. Acceso el: 9 ene. 2021.

INEGI - Instituto Nacional de Estadística y Geografía. Encuesta Nacional de Ingresos y Gastos de los Hogares (ENIGH) 2010. México, 2010. Disponible en: https://www.inegi.org.mx/programas/ enigh/tradicional/2010/. Acceso el: 9 ene. 2021.

INEGI - Instituto Nacional de Estadística y Geografía. Encuesta Nacional de Ingresos y Gastos de los Hogares (ENIGH) 2012. México, 2012. Disponible en: https://www.inegi.org.mx/programas/ enigh/tradicional/2012/. Acceso el: 9 ene. 2021.

INEGI - Instituto Nacional de Estadística y Geografía. Encuesta Nacional de Ingresos y Gastos de los Hogares (ENIGH) 2014. México, 2014. Disponible en: https://www.inegi.org.mx/programas/ enigh/tradicional/2014/. Acceso el: 9 ene. 2021.

INEGI - Instituto Nacional de Estadística y Geografía. Resultado Encuesta Nacionl de Ingreso Gasto de los Hogares 2014. México, 2014. Disponible en: https://www.inegi.org.mx/programas/ enigh/tradicional/2014/. Acceso el: 9 ene. 2021.

HAM, R. El envejecimiento en México: el siguiente reto de la transición demográfica. Ciudad de México: El Colegio de la Frontera Norte, A. C. y Miguel Ángel Porrúa, 2003. 
LEE, R.; MASON, A. Theoretical aspects of national transfer accounts. In: LEE, R.; MASON, M. (org.). Population aging and the generational economy: a global perspective. Reino Unido: Edward Elgar Publishing, 2011. p. 32-54.

MARTíN, J. A.; GARCIAS, L. P. El consumo y la tasa de ahorro privados de los hogares españoles: una descomposición de los efectos edad y cohorte. Investigaciones Económicas, v. 32, n. 1, p. 87-121, 2008.

MEJÍA-GUEVARA, I.; MURGUÍA, V. Participación laboral y dividendos demográficos. Revista Coyuntura Demográfica, n. 2, p. 87-92, 2012. Disponible en: https://www.researchgate.net/ profile/Ivan-Mejia-Guevara/publication/283794892_Participacion_laboral_y_dividendos_ demograficos/links/5647596308ae9f9c13e931c9/Participacion-laboral-y-dividendosdemograficos.pdf.

MEJÍA-GUEVARA, I.; FERNÁNDEZ VARELA, F. V.; GARCÍA LÓPEZ, J. E. El primer dividendo demográfico y los sistemas de protección social en México. Notas de Población, v. XXXVII, n. 90, p. 133-162, 2010.

MEJÍA-GUEVARA, I. Ciclo de vida económico en México. In: VÉLEZ, F. (ed.). La situación demográfica de México 2008. Ciudad de México: Consejo Nacional de Población (CONAPO), 2008. p. 31-44.

MEJÍA-GUEVARA, I. Ciclo de vida económico: 1992-2010. In: RABELL, C. (ed.). Los mexicanos: un balance del cambio demográfico. Ciudad de México: Fondo de Cultura Económica, 2014. p. 733-784.

MEJÍA-GUEVARA, I. Economic inequality and intergenerational transfers: evidence from Mexico. The Journal of the Economics of Ageing, v. 5, n. C, p. 23-32, 2015.

MEJÍA-GUEVARA, I. The economic lifecycle and intergenerational redistribution in Mexico. In: LEE, R.; MASON, A. (ed.). Population aging and the generational economy: a global perspective. Reino Unido: Edward Elgar Publishing, 2011. p. 283-296.

MEJÍA-GUEVARA, I.; RIVERO, E.; NAVA, I. Transferencias intergeneracionales por género y efectos económicos del envejecimiento demográfico en México. Notas de Población, v. 46, n. 108, p. 69-97, 2019. Disponible en: https://www.cepal.org/sites/default/files/publication/ files/44678/S1900093_MejiaGuevara_es.pdf.

MODIGLIANI, F. Utility analysis and the consumption function: an interpretation of cross-section data. In: MODIGLIANI, F. (org.). The collected papers of Franco Modigliani. Estados Unidos: MIT Press, 2005. p. 3-46.

MODIGLIANI, F.; BRUMBERG, R. Utility analysis and consumption function: an interpretation of cross-section data. In: KURITHARA, K. (ed.). Post-keynesian economics. New Brunswick: Rutgers University Press, 1954. p. 388-436.

NAVA, I. Ahorro y seguridad social en los hogares de México. Revista Latinoamericana de Población, v. 9, n. 17, p. 61-82, 2015.

OCDE - Organización para la Cooperación y el Desarrollo Económicos 2019. Disponible en: https://www.oecd.org//. Acceso el: 9 ene. 2021.

RENTERÍA E.; SOUTO, G.; MEJÍA, I.; PATXOT, C. The effect of education on the demographic dividend. Population and Development Review, v. 42, n. 4, p. 651-671, 2016.

SANCHEZ, L.; PACHECO, E. Rural population trends in Mexico: demographic and labor changes. In: KULCSÁR J.; CURTIS K. J. (org.). International handbook of rural demography. Estados Unidos: Springer, 2012. v. 3, p. 155-168. 
SOLÍS, F.; VILLAGÓMEZ, A. Ahorro y pensiones en México: un estudio al nivel de las familias. Economía Mexicana, v. 8, n. 2, p. 339-365, 1999. Disponible en: http://repositorio-digital.cide. edu/handle/11651/4191.

SPECKMAN, P. Kernel smoothing in partial linear models. Journal of the Royal Statistical Society: Series B (Methodological), v. 50, n. 3, p. 413-436, 1988.

SZÉKELY, M. Monto y distribución del ahorro de los hogares en México. El Trimestre Económico, v. 65, n. 2, p. 263-313, 1998.

SZÉKELY, M.; MENDOZA, P. Descomponiendo los cambios en la pobreza de ingresos en México: aspectos metodológicos y su aplicación para el período 1994-2014. Gobierno de México, 2016. Disponible en: https://www.gob.mx/cms/uploads/attachment/file/109697/Descomposicion_ de_Cambios_en_la_Pobreza_-_Informe_Final_EASE_-_13_Mayo_2016.pdf. Acceso el: 10 sep. 2020.

VÁZQUEZ, D.; BARBOSA, E. Consideraciones metodológicas y el contexto histórico del ahorro y los adultos mayores en México. Nóesis. Revista de Ciencias Sociales y Humanidades, v. 22, n. 43-1, p. 214-251, 2013

VERBEEK, M. Pseudo-panels and repeated cross-sections. In: MÁTYÁS, L.; SEVESTRE, P. (org.). The econometrics of panel data. Berlín Heidelberg: Springer-Verlag, 2008. p. 369-383.

VILLAGÓMEZ, A.; ZAMUDIO, A. Household saving in Mexico. Toluca: Centro de Investigación y Docencia Económicas (CIDE), 1997. (Documento de Trabajo del, n. 78). Disponible en: http:// citeseerx.ist.psu.edu/viewdoc/download?doi=10.1.1.817.1523\&rep=rep1\&type=pdf.

VILLAGÓMEZ, A.; ZAMUDIO, A. Household saving, human capital accumulation and labor force participation chances in the Mexican rural sector. Toluca: Centro de Investigación y Docencia Ecónomicas (CIDE), 1999.

WONG, R.; ESPINOZA, M. Ingreso y bienes de la población de edad media y avanzada en México. Papeles de Población, v. 9, n. 37, p. 129-166, 2003.

\section{Sobre los autores}

Isalia Nava Bolaños es doctora en Estudios de Población por El Colegio de México. Investigadora en el Instituto de Investigaciones Económicas de la Universidad Nacional Autónoma de México.

Gonzalo Esteban Negreros Amaya es maestro en Economía por la Universidad Nacional Autónoma de México. Docente en la Facultad de Economía de la Universidad Nacional Autónoma de México.

Abraham Granados Martínez es doctor en Economía por la Universidad Nacional Autónoma de México. Investigador en el Instituto de Investigaciones Económicas de la Universidad Nacional Autónoma de México.

\section{Dirección para correspondencia}

Isalia Nava Bolaños

Instituto de Investigaciones Económicas

Circuito Mario de la Cueva, Ciudad de la Investigación en Humanidades, C.U., Coyoacán

04510 - Ciudad de México, México 


\author{
Gonzalo Esteban Negreros Amaya \\ Facultad de Economía \\ Interior S/N, C.U., Coyoacán \\ 04510 - Ciudad de México, México \\ Abraham Granados Martínez \\ Instituto de Investigaciones Económicas \\ Circuito Mario de la Cueva, Ciudad de la Investigación en Humanidades, C.U., Coyoacán \\ 04510 - Ciudad de México, México
}

\title{
Abstract
}

Saving Profiles in Mexican Households. Does the Place of Residence Matter?

This paper analyzes the saving profile of rural and urban Mexican households. Based on the National Survey of Household Income and Expenditure from 1994 to 2014, a synthetic panel is constructed and a semi-parametric model is estimated to identify profiles by age. Results show a contrast with the life cycle hypothesis. The age profile does not show an inverted $U$ shape and there is evidence of greater savings in advanced ages. Saving profiles are higher in urban households, particularly for the elderly and regarding access to health.

Keywords: Life cycle hypothesis. Semi-parametric model. Pseudo-panel method.

\section{Resumo}

Poupança em famílias no México: o local de residência é importante?

Este artigo analisa o perfil de poupança de famílias rurais e urbanas no México. Com base na Pesquisa Nacional de Renda e Despesa Domiciliar de 1994 a 2014, é construído um painel sintético e estimado um modelo semiparamétrico que permite identificar os perfis por idade. Os resultados contrastam com a hipótese do ciclo de vida. 0 perfil da idade não apresenta a forma de $U$ invertido e há evidências de maior economia em idades avançadas. Os perfis de poupança são mais elevados nos domicílios urbanos, especialmente naqueles com idosos e com acesso à saúde.

Palavras-chave: Hipótese do ciclo de vida. Modelo semiparamétrico. Método do pseudopanel. 